\title{
Study on lumbar kinematics and the risk of low back disorder in female university students by using shoes of different heel heights ${ }^{1}$
}

\author{
Rauf Iqbal ${ }^{\mathrm{a}^{*}}$, Amitabha De ${ }^{\mathrm{b}}$, Wricha Mishra ${ }^{\mathrm{c}}$, Shreya Maulik ${ }^{\mathrm{c}}$ and Chandra $\mathrm{AM}^{\mathrm{d}}$ \\ ${ }^{a}$ Assistant Professor, National Institute of Industrial Engineering, Vihar lake, Mumbai, India. \\ ${ }^{b}$ Professor, National Institute of Industrial Engineering, Vihar lake, Mumbai, India. \\ ${ }^{c}$ Research Fellow, National Institute of Industrial Engineering, Vihar lake, Mumbai, India \\ ${ }^{d}$ Professor, University of Calcutta, Kolkata, India
}

\begin{abstract}
The study was taken up to investigate the effects of heel heights on lumbar kinematics and the risk of Low Back Disorder (LBD) in females. Nineteen female university students (24.5 \pm 3.36 yrs) volunteered in the study. Lumbar kinematics was measured by using Industrial Lumbar Motion Monitor (iLMM). The volunteers were asked to walk for a distance of 50 meters in 3 different given conditions i.e bare foot (Heel 0), with flat heels (Heel 1) and with high heels (Heel 2). Heights of Heel 1 and Heel 2 were $1.5 \pm 0.84 \mathrm{~cm}$ and $5.5 \pm 1.70 \mathrm{~cm}$ respectively. The Lumbar kinematic parameters studied were- Average Twisting Velocity (ATV), Maximum Sagital Flexion (MSF) and Maximum Lateral Velocity (MLV). It was observed that all the above mentioned Lumbar kinematics - ATV, MSF and MLV increases with increase of heel heights, which in turn increases the risk of LBD. As a result of increase in Lumbar kinematic values with increase in heel heights, LBD risk has also increased. Mean and SD of the LBD risk with Heel 0, Heel 1 and Heel 2 were $16.79 \pm 6.04 \%, 19.00 \pm 7.38 \%$ and $22.11 \pm 6.98 \%$ respectively. Lower stature with high heels showed higher risk of LBD than the higher stature with high heels.
\end{abstract}

Key words: iLMM, high heel, Lumbar kinematics, LBD

\footnotetext{
${ }^{1}$ Corresponding author. E-mail: rauf_iq@yahoo.com
} 


\section{Introduction}

A shoe is an item of footwear intended to protect and provide comfort to the human foot during day to day life. Today shoes are not just what we wear on our feet for protection, they are a fashion statement. Though shoes were originally intended to protect one's feet from various elements, today the shoe has evolved from its practical origins to grandiose heights, and at the highest level is of course, the high heel. Wearing high heels are not only considered as present day fashion and make the user feel taller but also a passion, personal expression, source of authority, sexual independence, mark of flaunted femininity, psychologically empowering and joy. It is a proven fact that high heels change the normal posture and gait of the body that causes health hazards, leading to back problem. High heel shoes put the foot in a plantar flexed position, which increase the pressure on the forefoot (ball of foot and toes) [4]. The lower part of the body leans forward and to compensate and balance, the upper part of the body leans backward. This disturbs the normal s-shaped curve of the spine $[2,5]$. Wearing high heels cause lumbar spine flattening and a posterior (backward) displacement of the head and thoracic spine. This poor alignment of the spine leads to its twisting and bending that result in muscle overuse and back pain [2]. High heels are preferred over the flat heels and are normally used with the formal dress by the females all over the world. The purpose of this study was to investigate the effects of heel heights on Lumbar kinematics and the risk of Low Back Disorder (LBD) in females.

\section{Method}

\subsection{Investigating subjects:}

The study was conducted on nineteen young female university students in the age range of 21-27 years. All subjects included were healthy; there were no incidence of serious neurological or musculoskeletal illness or injury at the time of the experiment. None of the subjects was using any prescribed medication at the time of testing. The volunteers were interviewed before inclusion in the study to categorise their activity levels. It was found that all the volunteers were physically active. The study was approved by the Institutional Ethical Committee, University of Calcutta, Kolkata.

\subsection{Instrumentation}

The study was conducted by using Industrial Lumbar Motion Monitor (iLMM), made BioDynamic Solutions, Inc. c/o NexGen Ergonomics, Inc. USA and Ballet 2.0 software, BIOMEC Inc. USA [1]. The iLMM is a tri-axial electrogoniometer that acts as a lightweight exoskeleton of the lumbar spine. It is positioned on the back of a subject directly in line with the spine and attached by harness at the pelvis and thorax. Four potentiometers at the base of the iLMM measure the instantaneous position of the spine in there-dimensional space relative to the pelvis, as the subject performs tasks. Position data from the potentiometers are recorded at $60 \mathrm{~Hz}$, transmitted to an analog-to-digital (A/D) converter, and then recorded on a microcomputer. The data are then processed to calculate the position, velocity and acceleration of the spine in each of the three planes of motion as a function of time. Measurements taken where accomplished through wireless telemetry from the iLMM to a laptop computer.

The iLMM exoskeleton was adjusted for the small, medium and large sized employees. The iLMM was adjusted at neutral position (Zeroing) by keeping it on a flat surface before the experiment for each individual. After adjusting the equipment it was put on the spine of the subject and was fixed on the back of the volunteers to track the motion of the low back in three-dimensional space [Fig 1]. 


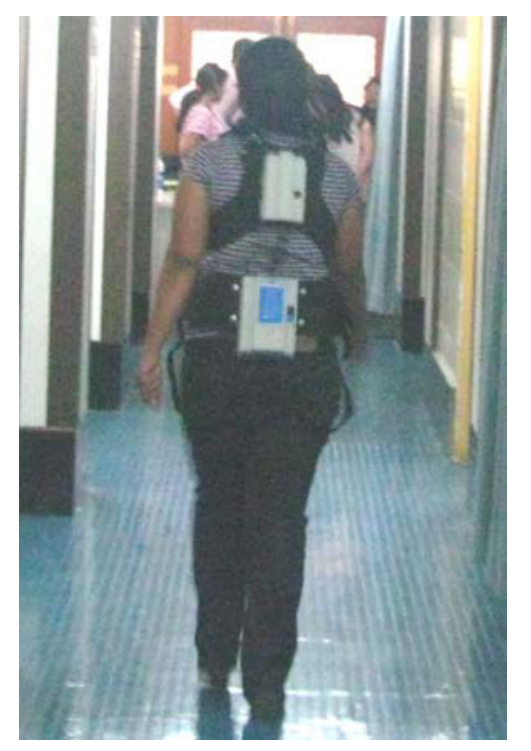

Fig 1: Recording of lumbar kinematics by iLMM

The volunteers were asked to walk straight-line at selfselected speed on the level ground for a distance of 50 meters in 3 different given conditions- i) bare foot [Heel 0] ii) with flat heels [Heel 1] and iii) with high heels [Heel 2] which most of them wear regularly with their formal dress. Lumbar kinematic parameters like Average Twisting Velocity, Maximum Sagital Flexion and Maximum Lateral Velocity were recorded by the iLMM and displayed online on the interfaced laptop through the Ballet 2.0 software during walking. Based on the Lumbar kinematics recorded, the software also predicted the risk of Low Back Disorder.

\section{Data analysis}

Following data collection, the data were viewed and analyzed using the Ballet 2.0 software. The data were time normalised with respect to the walking and movement of the lumbar. The Lumbar kinematic parameters for each trial with Heel 0, Heel 1 and Heel 2 and corresponding LBD risk were compared. Statistical analysis was performed using the Minitab statistical software.

\section{Results and discussion}

The age, height and weight of the subjects have been presented in Table 1. 
Table 1

Physical parameters of the subjects

\begin{tabular}{lccccc}
\hline Variables & $\begin{array}{c}\text { Age } \\
(\mathrm{yrs})\end{array}$ & $\begin{array}{c}\text { Height } \\
(\mathrm{cm})\end{array}$ & $\begin{array}{c}\text { Weight } \\
(\mathrm{kg})\end{array}$ & $\begin{array}{c}\text { Heel 1 } \\
(\mathrm{cm})\end{array}$ & $\begin{array}{c}\text { Heel 2 } \\
(\mathrm{cm})\end{array}$ \\
\hline Mean & 24.5 & 155.1 & 57.7 & 1.5 & 5.5 \\
\pm SD & 3.36 & 4.95 & 10.53 & 0.84 & 1.70 \\
Range & $21-29$ & $149-167.6$ & $42-76$ & $0.4-2.6$ & $4-8.5$ \\
\hline
\end{tabular}

Mean and SD of the age, height and weight of the volunteers were $24.5 \pm 3.36 \mathrm{yrs}, 155.1 \pm 4.95 \mathrm{cms}$ and $57.7 \pm 10.53 \mathrm{kgs}$ respectively. Heights of Heel 1 and Heel 2 were $1.5 \pm 0.84 \mathrm{~cm}$ and $5.5 \pm 1.70 \mathrm{~cm}$ respectively. The lumbar kinematic parameters studied were- Average Twisting Velocity, Maximum Sagital Flexion and Maximum Lateral Velocity [Fig 2]. Based on the above three parameters risk of Low Back
Disorder (LBD) was predicted by the Ballet 2.0 software [Fig 3]. It was observed that all the above mentioned Lumbar kinematics, namely Average Twisting Velocity, Maximum Sagital Flexion and Maximum Lateral Velocity are increasing with the increase of the heel heights, which in turn increases the risk of LBD.

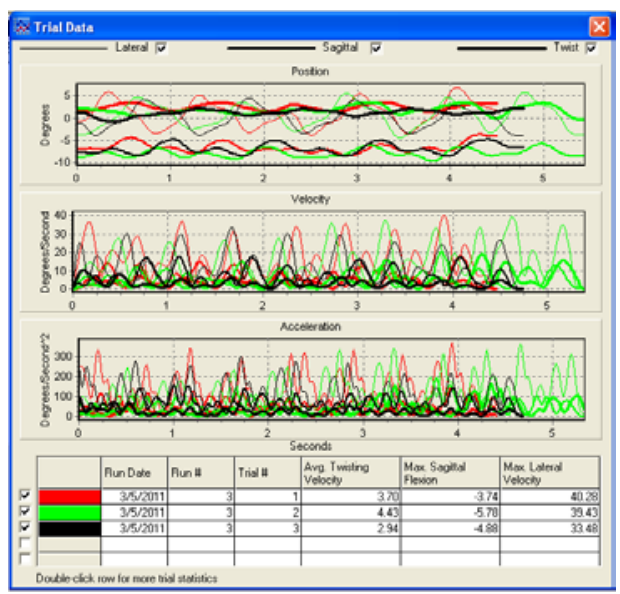

Fig 2: Graphical representation of lumbar kinematics

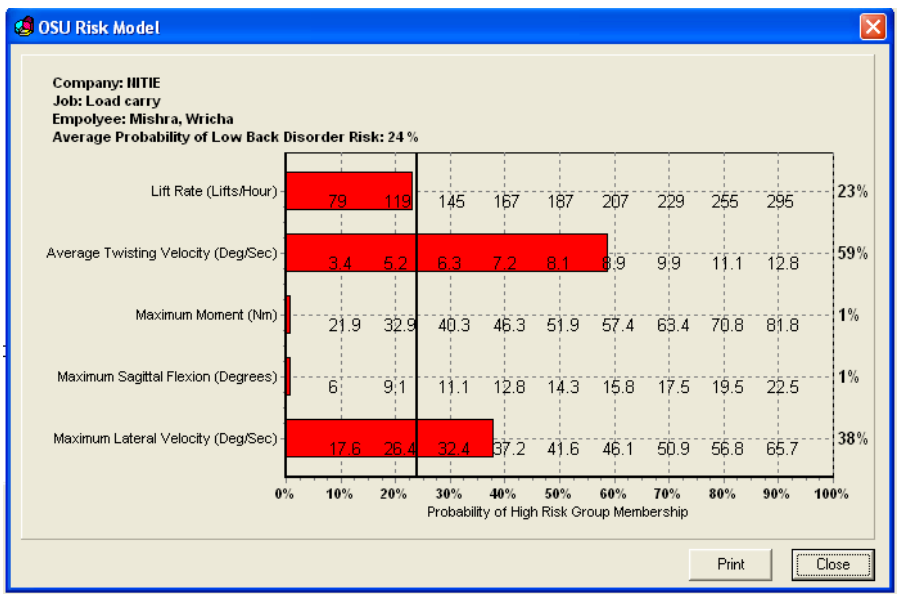

Fig 3: Risk of Low Back Disorder 
Table 2

Lumbar kinematics and the risk of LBD with heel heights

\begin{tabular}{|c|c|c|c|c|}
\hline $\begin{array}{l}\text { Heel } \\
\text { Type }\end{array}$ & $\begin{array}{c}\text { Average Twisting Velocity } \\
(\mathrm{deg} / \mathrm{sec})\end{array}$ & $\begin{array}{c}\text { Maximum Sagital Flexion } \\
(\mathrm{deg} / \mathrm{sec})\end{array}$ & $\begin{array}{l}\text { Maximum Lateral Velocity } \\
(\mathrm{deg} / \mathrm{sec})\end{array}$ & $\begin{array}{c}\text { Average probability of LBD } \\
(\%)\end{array}$ \\
\hline & $\begin{array}{l}\text { Mean } \pm \text { SD } \\
\text { (Range) }\end{array}$ & $\begin{array}{l}\text { Mean } \pm \mathrm{SD} \\
\text { (Range) }\end{array}$ & $\begin{array}{l}\text { Mean } \pm \text { SD } \\
\text { (Range) }\end{array}$ & $\begin{array}{l}\text { Mean } \pm \text { SD } \\
\text { (Range) }\end{array}$ \\
\hline \multirow[t]{2}{*}{ Heel 0} & $4.47 \pm 2.36$ & $0.46 \pm 5.26$ & $28.24 \pm 6.86$ & $16.79 \pm 6.04$ \\
\hline & $(1.04-10.16)$ & $(-13.58-6.35)$ & $(13.92-41.56)$ & $(6-30)$ \\
\hline \multirow[t]{2}{*}{ Heel 1} & $5.23 \pm 2.61$ & $0.93 \pm 5.40$ & $28.74 \pm 7.11$ & $19.00 \pm 7.38$ \\
\hline & $(1.87-11.48)$ & $(-12.66-7.96)$ & $(15.97-41.9)$ & $(7-35)$ \\
\hline \multirow[t]{2}{*}{ Heel 2} & $5.85 \pm 2.60$ & $1.21 \pm 5.19$ & $32.49 \pm 8.51$ & $22.11 \pm 6.98$ \\
\hline & $(2.1-13.03)$ & $(-12.79-7.71)$ & $(16.98-47.86)$ & $(8-39)$ \\
\hline
\end{tabular}

Mean and SD of the Average Twisting Velocity with Heel 0 , Heel 1 and Heel 2 were $4.47 \pm 2.36 \mathrm{deg} / \mathrm{sec}, 5.23 \pm 2.61 \mathrm{deg} / \mathrm{sec}$ and $5.85 \pm 2.60$ $\mathrm{deg} / \mathrm{sec}$ respectively. The ranges of Average Twisting Velocity with Heel 0, Heel 1 and Heel 2 were 1.04 $\mathrm{deg} / \mathrm{sec}$ to $10.16 \mathrm{deg} / \mathrm{sec}, 1.87 \mathrm{deg} / \mathrm{sec}$ to 11.48 $\mathrm{deg} / \mathrm{sec}$ and $2.1 \mathrm{deg} / \mathrm{sec}$ to $13.03 \mathrm{deg} / \mathrm{sec}$ respectively [Table 2].

Mean and SD of the Maximum Sagital Flexion with Heel 0 , Heel 1 and Heel 2 were $0.46 \pm 5.26$ degree, $0.93 \pm 5.40$ degree and $1.21 \pm 5.19$ degree respectively. The ranges of Maximum Sagital Flexion with Heel 0, Heel 1 and Heel 2 were -13.58 degree to +6.35 degree, -12.66 degree to +7.96 degree and 12.79 degree to +7.71 degree respectively [Table 2].

Mean and SD of the Maximum Lateral Velocity with Heel 0, Heel 1 and Heel 2 were $28.24 \pm 6.86$ $\mathrm{deg} / \mathrm{sec}, 28.74 \pm 7.11 \mathrm{deg} / \mathrm{sec}$ and $32.49 \pm 8.51 \mathrm{deg} / \mathrm{sec}$ respectively. The ranges of Maximum Lateral Velocity with Heel 0, Heel 1 and Heel 2 were 13.92 $\mathrm{deg} / \mathrm{sec}$ to $41.56 \mathrm{deg} / \mathrm{sec}, 15.97 \mathrm{deg} / \mathrm{sec}$ to 41.9 $\mathrm{deg} / \mathrm{sec}$ and $16.98 \mathrm{deg} / \mathrm{sec}$ to $47.86 \mathrm{deg} / \mathrm{sec}$ respectively. As a result of increase in lumbar kinematic values with increase in heel heights, LBD risk has also increased. The mean and SD of the LBD risk with Heel 0, Heel 1 and Heel 2 were $16.79 \pm 6.04 \%, \quad 19.00 \pm 7.38 \%$ and $22.11 \pm 6.98 \%$ respectively. The ranges of LBD risk with Heel 0 , Heel 1 and Heel 2 were $6-30 \%, 7-35 \%$ and $8-39$ $\%$ respectively [Table 2]. Analysis of the data shows that risk of LBD has marked correlation with Average Twisting Velocity $(\mathrm{r}=0.87)$, Maximum Sagital Flexion $(r=0.47)$ and Maximum Lateral Velocity $(r=$ 0.70) which are dependent on the stature of the subjects and height of the heels.

High-heeled shoes slant the foot forward and down while bending the toes up. The more that the feet are forced into this position, the more it may cause the Achilles tendon to shorten [3]. When the foot slants forward, a much greater weight is transferred to the ball of the foot and the toes, increasing the likelihood of damage to the underlying soft tissue that supports the foot. High heels-because they tip the foot forward-put pressure on the lower back through making the rump push outwards and crushing the lower back vertebrae and contracting the muscles of the lower back and generating LBD [6,7].

Comparison of the risk of Risk of LBD with various parameters shows that use of heels and probability of LBD is dependent on the stature of the users. Lower stature with increase in heel heights showed higher risk of LBD in comparison to the higher stature with high heels [Table 3]. 
Table 3

Comparison of heel heights and risk of LBD

\begin{tabular}{|c|c|c|c|c|c|c|}
\hline \multirow[t]{4}{*}{ Stature } & \multicolumn{3}{|c|}{ Risk of LBD (\%) } & \multicolumn{3}{|c|}{ Correlation \& $(\mathrm{P})$ for risk of LBD } \\
\hline & Heel 0 & Heel 1 & Heel 2 & Heel 0 & Heel 0 & Heel 1 \\
\hline & & & & vs & vs & vs \\
\hline & Mean \pm SD & Mean \pm SD & Mean \pm SD & Heel 1 & Heel 2 & Heel 2 \\
\hline Stature (upto $152 \mathrm{~cm}$ ) & $17.31 \pm 5.38$ & $20.00 \pm 6.96$ & $23.08 \pm 6.41$ & $\begin{array}{c}0.89 \\
(\mathrm{P}<0.01)\end{array}$ & $\begin{array}{c}0.87 \\
(\mathrm{P}<0.001)\end{array}$ & $\begin{array}{c}0.85 \\
(\mathrm{P}<0.01)\end{array}$ \\
\hline Stature (above $152 \mathrm{~cm}$ ) & $15.67 \pm 7.74$ & $16.83 \pm 8.47$ & $20.00 \pm 8.32$ & 0.82 & 0.81 & 0.90 \\
\hline & & & & Ns & Ns & Ns \\
\hline
\end{tabular}

It was found that in case of stature upto $152 \mathrm{~cm}$ (average Indian female height) there is a significant difference in the risk of LBD observed from Heel 0 and Heel $1(\mathrm{p}<0.01)$, Heel 0 and Heel $2(\mathrm{p}<0.001)$ also Heel 1 and Heel $2(p<0.01)$. But in case of the stature above $152 \mathrm{~cm}$, the risk of LBD with increase in

\section{Conclusion}

A high heel shoe put the foot in a plantarflexed (foot pointed downward) position, placing an increased amount of pressure on the forefoot. This causes the user to adjust the rest of the body to maintain proper balance. The lower part of the body leans forward and to compensate for that, the upper part of the body must lean back to keep the user balanced. This shift in posture form the normal posture develops the risk of LBD. Females upto their average Indian heights $(152 \mathrm{~cm})$ are more prone to develop LBD with regular use of high heels but the females above $152 \mathrm{~cm}$ is lesser prone to develop LBD with high heels. But despite the adverse consequences high heeled shoes are popular as they are elegant and fashionable. If it is not possible to avoid high heels altogether, it is suggested that the high heeled shoes should not be used regularly, flat heel should also be used at frequent time. This will not only reduce the risk of LBD but also prevent shortening of calf muscle and stiffening of tendon in the ankle, which will prevent leg pain among the high heel users. heel heights (used in the present experiment) does not differ significantly [Table 3]. This indicates that females upto their average Indian heights $(152 \mathrm{~cm})$ are more prone to develop LBD with regular use of high heels but the females above $152 \mathrm{~cm}$ is lesser prone to develop LBD with high heels.

\section{References}

[1] BioDynamic Solutions, Inc. c/o NexGen Ergonomics, Inc. USA and Ballet 2.0 software, BIOMEC Inc. USA, 2001

[2] J. Crosbie, R. Vachalathitib and R, Smith, Patterns of spinal motion during walking, Gait\&Posture, 1997, 5: 612

[3] Marco Narici et.al, Persistent usage of high-heel shoes, Journal of Experimental Biology. 2010, July, p. 84.

[4] M.J. Coughlin, The high cost of fashionable footwear, $J$ Musculoskel Med., 1994,11:40-53.

[5] R.E. Snow, K.R. Williams, High heeled shoes: their effect on center of mass position, posture, threedimensional kinematics, rear foot motion, and ground reaction forces. Arch Phys Med Rehabil., 1994 May;75(5):568-76.

[6] W.S. Marras, S.A. Lavender, S. Leurgans, S. Rajulu, W.G. Allread, F.Fathallah, and S.A. Ferguson, The Role of Dynamic Three Dimensional Trunk Motion in Occupationally-Related Low Back Disorders: The Effects of Workplace Factors, Trunk Position and Trunk Motion Characteristics on Injury, Spine, 1993, 18(5):617-628.

[7] W.S. Marras, W.G. Allread, and R.G. Ried, Occupational Low Back Disorder Risk Assessment Using the Lumbar Motion Monitor, in Karwowski, W., and Marras, W.S., eds., The Occupational Ergonomics Handbook, CRC Press, Boca Raton, FL, 1999, 10751100 . 